Article

\title{
Evaluation of Using Gas Turbine to Increase Efficiency of the Organic Rankine Cycle (ORC)
}

\author{
Dominika Matuszewska $^{1}(\mathbb{D})$ and Piotr Olczak ${ }^{2, *}$ (D) \\ 1 AGH University of Science and Technology, 30 Mickiewicza Ave., 30-059 Cracow, Poland; \\ dommat@agh.edu.pl \\ 2 Mineral and Energy Economy Research Institute, Polish Academy of Sciences, 7A Wybickiego St., \\ 31-261 Cracow, Poland \\ * Correspondence: olczak@min-pan.krakow.pl
}

Received: 28 February 2020; Accepted: 20 March 2020; Published: 22 March 2020

\begin{abstract}
Power conversion systems based on the Organic Rankine Cycle (ORC) have been identified as a potential technology especially in converting low-grade renewable sources or waste heat. However, it is necessary to improve efficiency of ORC systems. This paper focuses on use of low geothermal resources (for temperature range of $80-128^{\circ} \mathrm{C}$ and mass flow $100 \mathrm{~kg} / \mathrm{s}$ ) by using modified ORC. A modification of conventional binary power plant is conducted by combining gas turbines to increase quality of steam from a geothermal well. An analysis has been conducted for three different working fluids: R245fa, R1233zd(E) and R600. The paper discusses the impact of parameter changes not only on system efficiency but on other performance indicators. The results were compared with a conventional geothermal Organic Rankine Cycle (ORC). Increasing of geothermal steam quality by supplying exhaust gas from a gas turbine to the installation has a positive effect on the system efficiency and power. The highest efficiency of the modified ORC system has been obtained for R1233zd(E) as a working fluid and it reaches values from $12.21 \%$ to $19.20 \%$ (depending on the temperature of the geothermal brine). In comparison, an ORC system without gas turbine support reaches values from $9.43 \%$ to $17.54 \%$.
\end{abstract}

Keywords: Organic Rankine Cycle; ORC; gas turbine; efficiency; geothermal heat source; binary power plant

\section{Introduction}

In recent years, energy is considered to be one of the basic factors conditioning the growth of individual countries, as well as one of the basic goods, without which economic development is inhibited. An increased demand can already be noticed for electric energy as well as problems related to this. Growing awareness of the effects of energy on global warming, the ozone layer depletion and on the environment together with increasing prices result in that waste heat and renewable energy sources are more and more used to produce electricity [1].

To convert low-temperature heat sources, Organic Rankine Cycle (ORC) is considered to be a leading technology. The simplicity, reliability, and flexibility of ORC is due to the fact that it can be successfully applied to used heat from renewable sources (solar energy [2-5], geothermal energy [6-17], biomass [18-22]) and waste heat processes [23].

In the electricity production sector, geothermal energy is one of the reliable alternative energy sources and is widely used in the world-to a large extent its use is limited by the temperature and mass flow of the geothermal water available from the production well. Moreover, unlike other renewable sources is its independent from seasonal, climatic, and geographical conditions [24]. The conversion of geothermal energy into electric energy plays an important role in saving energy resources. However, 
the output power of such a system is directly related to the parameters of steam entering the turbine, and thus with the quality of used geothermal brine. In the case of high temperature geothermal resources, there is no problem with efficient electric energy production. However, use source with lower parameters can be more complicated. Currently, the best solution to use the low-temperature heat source is through the binary power plant [25]. In terms of medium and large-scale power plants, the ORC technology is well-known and mature. However, the situation changes in the case of small-scale ORC systems - there are plenty of problems with system layout, working fluid selection and expander design which should be considered in light of specific conditions [24,26].

Since the optimal resource use is determined by working fluid selection, many studies about ORC focuses on that. Hung et al. [27] studied several working fluids candidates and concluded that the shape of the saturated vapor curve has huge impact on the ORC system design and its performance. Chen et al. [28] studied 35 wet, isentropic, and dry working fluids for ORCs and supercritical Rankine cycle. The work showed that the cycle performance is strongly depended from the working fluid selection and also that isentropic and dry fluids are most suitable for ORC cycles. Saleh et al. [14] investigated 31 pure fluids from different chemical classification (alkanes, fluorinate alkanes, ethers, and fluorinate ethers) suitable for low-temperature geothermal resource. The subcritical and supercritical processes were analyzed and limited by a temperature of $100{ }^{\circ} \mathrm{C}$. Also, recommendations for using an internal heat exchanger, in case the vapor leaving the turbine is superheated, are given. Quoilin et al. [29] showed that different objective functions in thermodynamic and economic optimization leads into different optimal operating conditions for the same working fluid. Fernandez et al. [30] investigate the use of siloxanes as working fluid for high temperature ORCs. Liu et al. [31] investigated hydrofluoroolefins (HFOs) as novel working fluids dedicated especially to ORC systems. The work investigated their potential as a replacement of traditional refrigerants in ORC installations due to their good impact on environment zero ODP (Ozone Depletion Potential) and a very low GWP (Global Warming Potential). They found that some of the investigated HFOs obtained promising system efficiency especially for low and medium temperature geothermal ORC power generation. Matuszewska et al. [32] showed that in dry and isentropic ORC fluids exist a low stability region in the dense vapors. It causes that both in the thermodynamic parameters and compressible flow conditions, some peculiarities in fluid behavior occur. That should be considered during working fluid selection and expander design process.

The use of Organic Rankine Cycle for the recovery of the exhausted gases heat from engines, turbines and industrial waste heat have been successfully applied in many cases [33-36]. Considering that about $30 \%$ of the fuel chemical energy is wasted as the exhausted gases, there is plenty room to usefully recovery of those waste heat [37]. Mostly, the Organic Rankine Cycle (ORC) is used as the bottom one to use the gas turbine waste heat [38-43].

However, more than $80 \%$ of the energy input in a conventional geothermal power plant is wasted as heat instead of converting into electricity. The superheat degree of vapor from geothermal brine is low, it would be much better to heated it before expanding it in a steam turbine. Such an action could improve a thermal efficiency of the geothermal power plant. Bidini et al. [44] showed how the geothermal steam quality increased by heating and lead to improvement of the performance of the conventional geothermal power plant. Astina et al.'s [45] work went further to improve the parameters of geothermal system. To enhance a geothermal power plant, a hybrid system was proposed. Some modification of conventional geothermal power plant was introduced such as combining it with a gas turbine, a refrigeration heat-pumps and Organic Rankine Cycle. The system efficiency improved significantly from $19.85 \%$ to $35.8 \%$. Both discussed works show that there is the possibility of improving the geothermal power plant by connecting with a conventional (fossil fuel) power plant. A more open view to discuss geothermal heat use for power generation based on a modified ORC system is presented in next sections.

Based on the references above, previous investigations have mainly focused on the use of waste heat (including exhaust gas from gas turbine) or renewable resources. There is not much study about 
increasing temperature of geothermal brine entering the binary power plant. The novelty of this paper is in analyzing and modeling such modified ORC cycle, where gas turbine has been used as a support subsystem to increase the enthalpy of geothermal brine. Proposed modified ORC system can be used in region with low and medium temperature geothermal resource to use such source in much more efficient way. The main object of this study focused on modeling modified ORC system to increase geothermal steam quality and evaluating the thermodynamic parameters changes for three different working fluids: R245fa, R600 and R1233zd(E). The paper is structured as follows. In Section 2, the modified ORC system model is described, both with main equation, methodology and model assumption, results and discussion about system modification are summarized in Section 3, and finally conclusions are provided in Section 4.

\section{System Model}

This section presents a modification of ORC cycle by introducing a gas turbine to increase the efficiency of the system using low and medium temperature geothermal heat. In this study, the idea of operating binary power plant with a gas turbine to provide sinuously electricity and heat is discussed with basic balance equations and a calculation method. So far, several analyses focused on ORC-gas turbine combined systems were presented [46,47], but most of the available materials focus on basic solutions of the low-temperature ORC cycles or gas turbines as independently operating systems $[8,48]$.

A modification of conventional binary power plant is conducted by combining gas turbines to increase the efficiency of the overall system. The proposed system consists of extraction and injection installation (supplying and using geothermal brine with specified parameters), gas turbine, ORC power plant and heat receiver (for technological or heating purposes). The diagram of the analyzed modified system together with the individual markings is presented in the figure below (Figure 1).

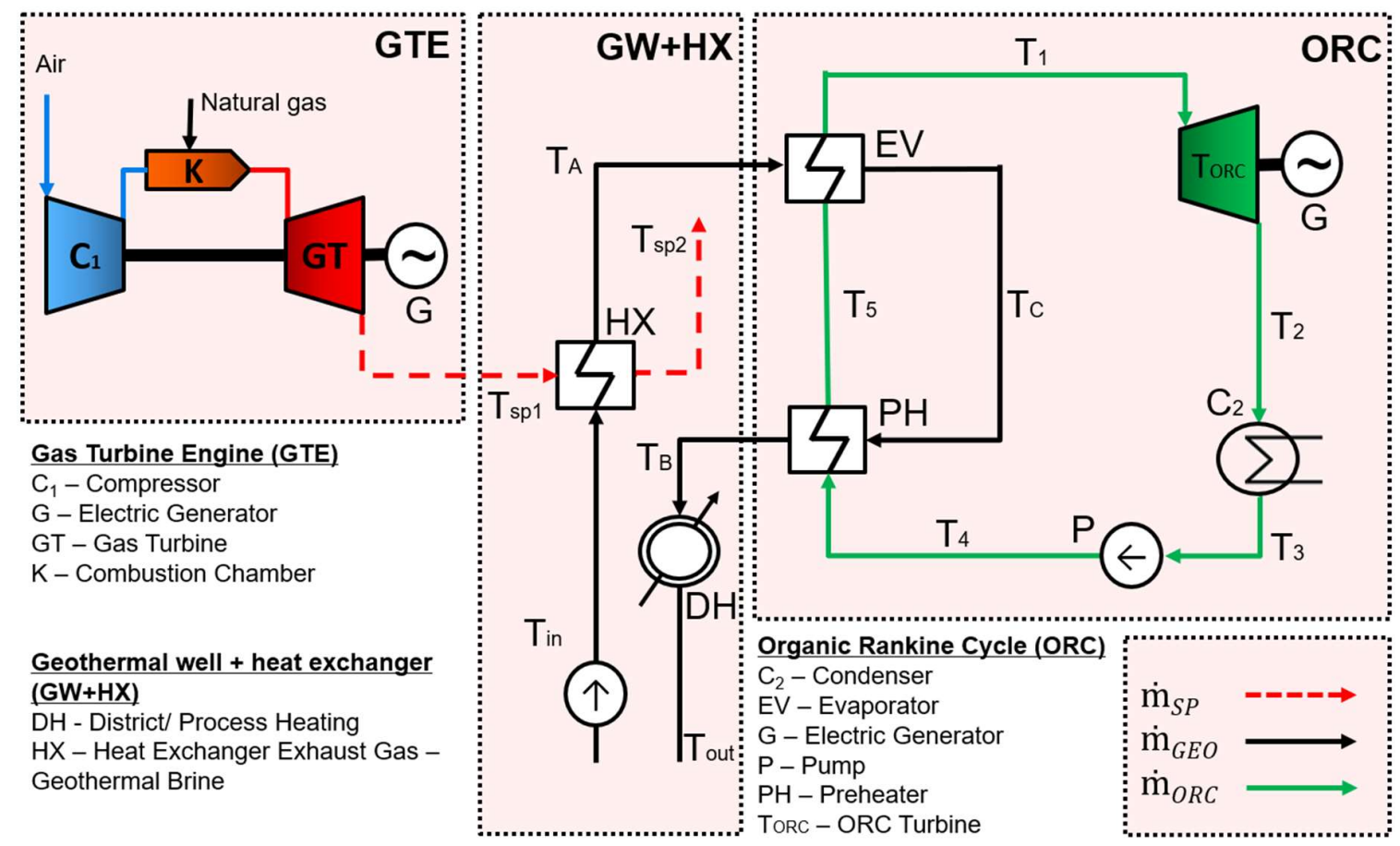

Figure 1. Simplified scheme of a modified ORC system supported by a gas turbine.

In the presented scheme, the stream of geothermal brine $\dot{m}_{G E O}$ at the temperature $T_{G E O} I N$, extracted from the extraction well, is directed to the ORC power plant. On the way, it is possible to heat this stream using hot flue gas fed to the heat exchanger from the gas turbine system. Then geothermal brine with elevated temperature $T_{G E O \_} A$ is directed to the evaporator. In the evaporator, the heat 
from the brine is transferred to the organic working fluid with low-boiling point, which causes fluids evaporation to $T_{1}$, while lowering the brine temperature to $T_{G E O} C$.

After the evaporator, the geothermal brine is directed to the counter-current heat exchanger, where the ORC fluid is preheated to the temperature $T_{5}$. Behind the heater, brine at temperature $T_{G E O} B$ still has relatively high parameters that can be used for energy purposes. Therefore, it is directed to the heat receiver to use its energy for technological or heating purposes. Then the brine at $T_{\text {GEO_OUT }}$ is directed to the injection hole and returned to the geothermal bed.

An elementary part of the analyzed system is a simple ORC power plant whose working medium is an organic fluid with low-boiling point, circulating in installation with mass flow rate

$\dot{m}_{\text {ORC }}$. The ORC installation consists of a heater, an evaporator, a turbine (driving an electric generator), a condenser and a pump. The vapors of ORC fluid are expanded in a turbine, which they leave with a temperature of $T_{2}$ and are directed to the condenser. In the condenser, vapors give off heat to the cooling water in the process of cooling and then condensation. The pump transports the condensed medium at temperature $T_{4}$ to the heater and then to the evaporator.

\subsection{Technical Analysis}

The basic relationships used in the calculation of the energy balance of the analyzed modified ORC system and the basic parameters that will be analyzed are presented below. The starting point of the analysis was to determine the evaporation and condensation temperatures of the working fluid in the ORC power plant. Using REFPROP Version 10 software, NIST [49], the parameters of the working fluid state were determined at the characteristic points of the ORC cycle. The following procedure was followed [7]:

1. Specific enthalpy $h_{1}$ and specific entropy $s_{1}$ were determined based on the evaporation pressure of dry saturated steam $(x=1)$.

2. Considering the isentropic expansion of the working fluid's vapor in the turbine $\left(s_{1}=s_{2}\right)$ based on specific entropy $s_{1}$ and condensing pressure, specific enthalpy $h_{2 s}$ was determined.

3. Specific enthalpy $h_{2}$ was determined based on the condensation pressure of dry saturated steam $(x=1)$.

4. Specific enthalpy $h_{3}$ was determined based on the condensing pressure for the liquid state (on the saturation line $\mathrm{x}=0$ )

5. Based on the evaporation pressure for the liquid (on the boundary line), specific enthalpy $\mathrm{h}_{5}$ was determined.

Real parameters for points 2 and 4 can be calculated based on equations for internal efficiency of the turbine (Equation (1)) and pump (Equation (2)).

$$
\eta_{i T}=\frac{h_{1}-h_{2 r}}{h_{1}-h_{2 s}}
$$

where:

$h_{1}-h_{2 r}$-is the real decrease in enthalpy with the same pressure drop as in the case of isentropic transformation.

$$
\eta_{i P}=\frac{h_{4 \mathrm{~s}}-h_{3}}{h_{4 \mathrm{r}}-h_{3}}
$$

where:

$h_{4 r}-h_{3}$-is the real decrease in enthalpy with the same pressure drop as in the case of isentropic transformation 
An important element in the calculations was the determination of the output parameters of the geothermal brine, i.e., the mass flow rate $\dot{m}_{G E O}$ and its temperature $T_{G E O \_A}$.

The balance equation for heat exchange between geothermal brine and gas turbine exhaust gases can be represented by Equation (3):

$$
\dot{Q}_{S P}=\dot{m}_{S P} \cdot c_{S P} \cdot\left(T_{S P 1}-T_{S P 2}\right)=\dot{m}_{G E O} \cdot c_{G E O} \cdot\left(T_{G E O \_A}-T_{G E O \_I N}\right)
$$

By transforming the above equation, it is possible to calculate the temperature of the geothermal brine $T_{G E O \_}$supplied to the evaporator of the ORC power plant (heated by the exhaust gas stream from the gas turbine system):

$$
T_{G E O \_A}=T_{G E O \_I N}+\frac{\dot{m}_{S P} \cdot c_{S P} \cdot\left(T_{S P 1}-T_{S P 2}\right)}{\dot{m}_{G E O} \cdot c_{G E O}}
$$

The heat exchange between the geothermal brine and the organic working fluid occurs in the evaporator and the heater. The following relationships-Equations (5a) and (5b) describe the energy balance equations in the evaporator:

$$
\begin{gathered}
\dot{Q}_{E}=\dot{m}_{G E O} \cdot\left(h_{G E O_{A}}-h_{G E O_{C}}\right)=\dot{m}_{O R C} \cdot\left(h_{1}-h_{5}\right) \\
\dot{Q}_{E}=\dot{m}_{G E O} \cdot c_{G E O} \cdot\left(T_{G E O_{-} A}-T_{G E O_{-} C}\right)=\dot{m}_{O R C} \cdot c_{O R C} \cdot\left(T_{1}-T_{5}\right)
\end{gathered}
$$

Heater energy balance equations can be written using the following relationships-Equations (6a) and $(6 b)$ :

$$
\begin{gathered}
\dot{Q}_{P H}=\dot{m}_{G E O} \cdot\left(h_{G E O_{C}}-h_{G E O_{B}}\right)=\dot{m}_{O R C} \cdot\left(h_{5}-h_{4}\right) \\
\dot{Q}_{P H}=\dot{m}_{G E O} \cdot c_{G E O} \cdot\left(T_{G E O \_C}-T_{G E O \_B}\right)=\dot{m}_{O R C} \cdot c_{O R C} \cdot\left(T_{5}-T_{4}\right)
\end{gathered}
$$

Based on the above balance equations, the mass flow rate of ORC fluid-Equation (7) — can be determined:

$$
\dot{m}_{O R C}=\frac{\dot{m}_{G E O} \cdot c_{G E O} \cdot\left(T_{G E O \_A}-T_{G E O \_B}\right)}{h_{1}-h_{4 r}}
$$

Equation (8) defines the heat receiver energy balance equation for technological or heating purposes:

$$
\dot{Q}_{O}=\dot{m}_{G E O} \cdot c_{G E O} \cdot\left(T_{G E O \_B}-T_{G E O \_O U T}\right)
$$

Based on Equation (8), the temperature of the geothermal brine return into the injection well can be determined:

$$
T_{\text {GEO_OUT }}=T_{G E O \_B}-\frac{\dot{Q}_{O}}{\dot{m}_{G E O} \cdot c_{G E O}}
$$

Determination of individual parameters (temperature, enthalpy, pressure, mass flow) at the characteristic points of the designed installation allows calculating individual values determining the efficiency of the designed installation:

- $\quad$ ORC efficiency

$$
\eta_{\mathrm{ORC}}=\frac{\left(h_{1}-h_{2 r}\right)-\left(h_{4 \mathrm{r}}-h_{3}\right)}{h_{1}-h_{4 r}}
$$

- $\quad$ ORC cycle power

$$
N_{O R C}=\dot{m}_{G E O} \cdot\left[\left(h_{1}-h_{2 r}\right)-\left(h_{4 \mathrm{r}}-h_{3}\right)\right] .
$$

- $\quad$ Electrical power of the designed ORC power plant

$$
N_{e l_{O R C}}=\eta_{\mathrm{m}} \cdot \eta_{\mathrm{g}} \cdot N_{\text {ORC }}
$$


where

$\eta_{\mathrm{m}}:$ mechanical efficiency of the turbine

$\eta_{\mathrm{g}}$ : generator efficiency

The total electric power of the modified ORC installation can be determined as the sum of the electric power of the ORC power plant and the gas turbine system Equation (13):

$$
N_{c o m} \text { cycle }=N_{e l_{O R C}}+N_{e l}
$$

where:

$N_{e l} G T$ : electric power of the gas turbine

Fossil fuel use factor (FFUF) is defined as the ratio of the increase in power of the analyzed system to the amount of heat supplied by using fossil fuel (in this case to the gas turbine system) [45] and can be represented in the form of Equation (14):

$$
F F U F=\frac{N_{\text {com_cycle }}}{\dot{Q}_{T G}} .
$$

where:

$\dot{Q}_{T G}$ : heat flow addition to the gas turbine system

The efficiency of the entire proposed system has been defined as the sum of the electrical power of the system and thermal power to the amount of energy supplied to the system in the form of a geothermal heat flux and the heat flux added to the gas turbine system:

$$
\eta_{\text {modified_system }}=\frac{N_{\text {com_cycle }}+\dot{Q}_{O}}{\dot{Q}_{T G}+\dot{Q}_{G E O}}
$$

where:

$\dot{Q}_{G E O}:$ geothermal heat flux

The defined equations parameterizing the system were used to calculate the efficiency of the proposed system and its analysis.

\subsection{Model Assumptions}

The presented installation uses several assumptions and design simplifications for both geothermal heat mining and injection installation, gas turbine and ORC power plant. The analysis of the effectiveness of the presented modified system assumes that it is dedicated to Polish conditions. In Poland, the documented operating temperatures of exploitation geothermal deposit are $20-90{ }^{\circ} \mathrm{C}$ (in some cases they exceed $100^{\circ} \mathrm{C}$ ) [50]. In calculation, due to the possibility of using deposits to produce electricity, the lower limit was set at $80{ }^{\circ} \mathrm{C}$, while the upper limit was set at $128{ }^{\circ} \mathrm{C}$ (although it is not limited by Polish conditions) in calculations. The ms stream of geothermal brine was adopted based on the literature analysis $\dot{m}_{G E O}=100 \mathrm{~kg} / \mathrm{s}$ [7].

It was assumed in the calculations that the source of hot exhaust gases, supplied to the ORC power plant, is a $5.1 \mathrm{MW}$ gas turbine, whose basic technical parameters are given in Table 1. The turbine of this power is used, among other purposes, for the combined production of electricity and heat at the William Grant \& Sons distillery in Girvan (Scotland, United Kingdom) [51]. 
Table 1. Basic technical parameters of the GT-100 gas turbine. Source: Own study based on [51].

\begin{tabular}{cc}
\hline Type of the Gas Turbine & Gas turbine GT-100 \\
\hline Fuel & Natural gas, liquid fuel, dual fuel \\
Gross efficiency & $30.2 \%$ \\
Heat rate & $11,914 \mathrm{~kJ} / \mathrm{kWh}$ \\
Turbine speed & $17,384 \mathrm{rpm}$ \\
Pressure ration & $14.0: 1$ \\
Exhaust mass flow & $19.5 \mathrm{~kg} / \mathrm{s}$ \\
Exhaust temperature & $545^{\circ} \mathrm{C}$ \\
Power & $5.1 \mathrm{MW}_{\mathrm{e}}$ \\
\hline
\end{tabular}

In addition, it was assumed that as a result of heat transfer from hot flue gas to brine, the flue gas temperature drops to $T_{S P 2}=250^{\circ} \mathrm{C}$.

Comparing the modified system with the reference ORC power plant (without gas turbine system), there is no heat exchange between the exhaust gases and geothermal brine in the installation. The extracted geothermal brine is transported directly to the heater, therefore in this case it is assumed that $T_{G E O \_I N}=T_{G E O \_A}$.

In the design of the ORC cycle itself, it was assumed that all processes are carried out by an organic working fluid with low-boiling point. These processes are reversible in line with the transformations of the Rankine reference cycle.

The analysis was carried out for three working fluids: R245fa, R600 (isobutane), R1233zd (E). The properties of the ORC fluids used in evaluation are presented in Table 2.

Table 2. Properties of applied working fluids. Source: Own study based on $[49,52,53]$.

\begin{tabular}{ccccc}
\hline \multicolumn{2}{c}{ Working Fluid } & R245fa & R600 & R1233zd (E) \\
\hline Chemical Class & & HCF & HC & HCFO \\
& $\mathrm{T}_{\mathrm{bp}}(\mathrm{K})$ & 288.29 & 272.66 & 291.41 \\
Physical properties & $\mathrm{T}_{\mathrm{K}}(\mathrm{K})$ & 427.16 & 424.13 & 439.6 \\
& $\mathrm{P}_{\mathrm{K}}(\mathrm{MPa})$ & 3.651 & 3.796 & 3.6237 \\
Environmental & Atmospheric lifetime (day) & 6.2 & 0.018 & 26 \\
properties & ODP & 0 & 0 & $\cong 0$ \\
& GWP & 693 & $\cong 20$ & 1 \\
\hline
\end{tabular}

The working fluids adopted for the analysis were selected based on their properties and significance in ORC power plants: R600 and R245fa fluids are popular in ORC power plants, and their impact on the environment is quite diverse (R245fa fluid has a high GWP value, while R600 fluid-average). The third of the selected fluids $\mathrm{R} 1233 \mathrm{zd}(\mathrm{E})$ is the latest generation fluid from the group of hydrofluoroolefins, dedicated specifically to ORC cycle (while e.g., R600 is a popular refrigerant) with negligible negative impact on the environment [54,55].

Determining the condensation and evaporation temperatures of the refrigerant is crucial for the heat flow calculations of the ORC cycle. The condensation temperature of the ORC fluid is closely related to the temperature of the condenser cooling liquid and the assumed difference between condensing and cooling liquid temperatures [46]. A condensing temperature of $30^{\circ} \mathrm{C}$ was used for the calculation. However, the evaporation temperature depends on the temperature of the geothermal brine and the characteristics of the adopted evaporator. By determining the value of evaporation temperature, it is possible to determine the saturation pressure of working fluid at this temperature. The project assumes a pinch point temperature of $5 \mathrm{~K}$ and that the heating of the working medium (from $\mathrm{T}_{4}$ to $\mathrm{T}_{5}$ ) takes place in a counter-current heat exchanger, where the heat capacity stream of both fluids is equal. 
The efficiency levels of individual devices were adopted at different levels: internal turbine efficiency $85 \%$, internal pump efficiency $65 \%$, mechanical efficiency of the turbine $97 \%$, generator efficiency $97 \%$.

The project also assumes that the heat receiver provides $10 \mathrm{MW}$ of heat for technological and heating purposes.

\section{Results}

This section presents the results of parametric analysis for the designed ORC power plant installation fed by geothermal water heated by a flue gas from turbine. The analysis was carried out for three working fluids: R245fa, R1233zd (E) and R600. The thermal input provided by the geothermal well varies in range 10.27-14.29 MPa for R245fa, 10.05-13.09 MPa for R1233zd(E) and 10.23-14.32 MPa for R600. The thermal input provided by the gas turbine for ORC system is constant (around 5,7 MW) because of the assumptions made at the beginning of this analysis. Also, the strong correlation can be observed between the evaporation temperature of working fluid and the main assumptions done during analysis - the input parameters of the geothermal brine and gas turbine exhaust cause that the evaporation temperature is $1.2 \mathrm{~K}$ lower than assumed geothermal brine input temperature. The evaporation pressure of the working fluids varies in range $0.638-1.795 \mathrm{MPa}$ for R1233zd(E), 0.985-2.492 MPa for R600 and 0.765-2.202 MPa for R245fa. Also, the working fluids mass flow rate varies in range $26.5-36.4 \mathrm{~kg} / \mathrm{s}$ for R1233zd(E), $14.2-21.6 \mathrm{~kg} / \mathrm{s}$ for R600 and $27.4-41.0 \mathrm{~kg} / \mathrm{s}$ for R245fa. The condensation temperature of $30{ }^{\circ} \mathrm{C}$ has been used for the calculation, while the condensation pressure depends on working fluids and obtains $0.155 \mathrm{MPa}$ for R1233zd(E), $0.283 \mathrm{MPa}$ for R600 and 0.178 MPa for R245fa.

Figure 2 shows the dependence on the ORC cycle efficiency of the designed modified system as a function of geothermal brine temperature $\left(T_{G E O \_I N}=80-128{ }^{\circ} \mathrm{C}\right)$ in relation to selected ORC fluids: R245fa, R1233zd (E) and R600. It can be seen from the figure that the efficiency of the ORC cycle for all considered factors increases with the temperature of the geothermal brine. There are minimal differences between the efficiency of modified ORC system for all analyzed fluids. The highest efficiency was obtained for R1233zd (E) and depending on the temperature of the geothermal brine, this efficiency ranges from $12.21 \%$ to $19.20 \%$, while the lowest efficiency was obtained in the case of R245fa (12.06-18.73\%).

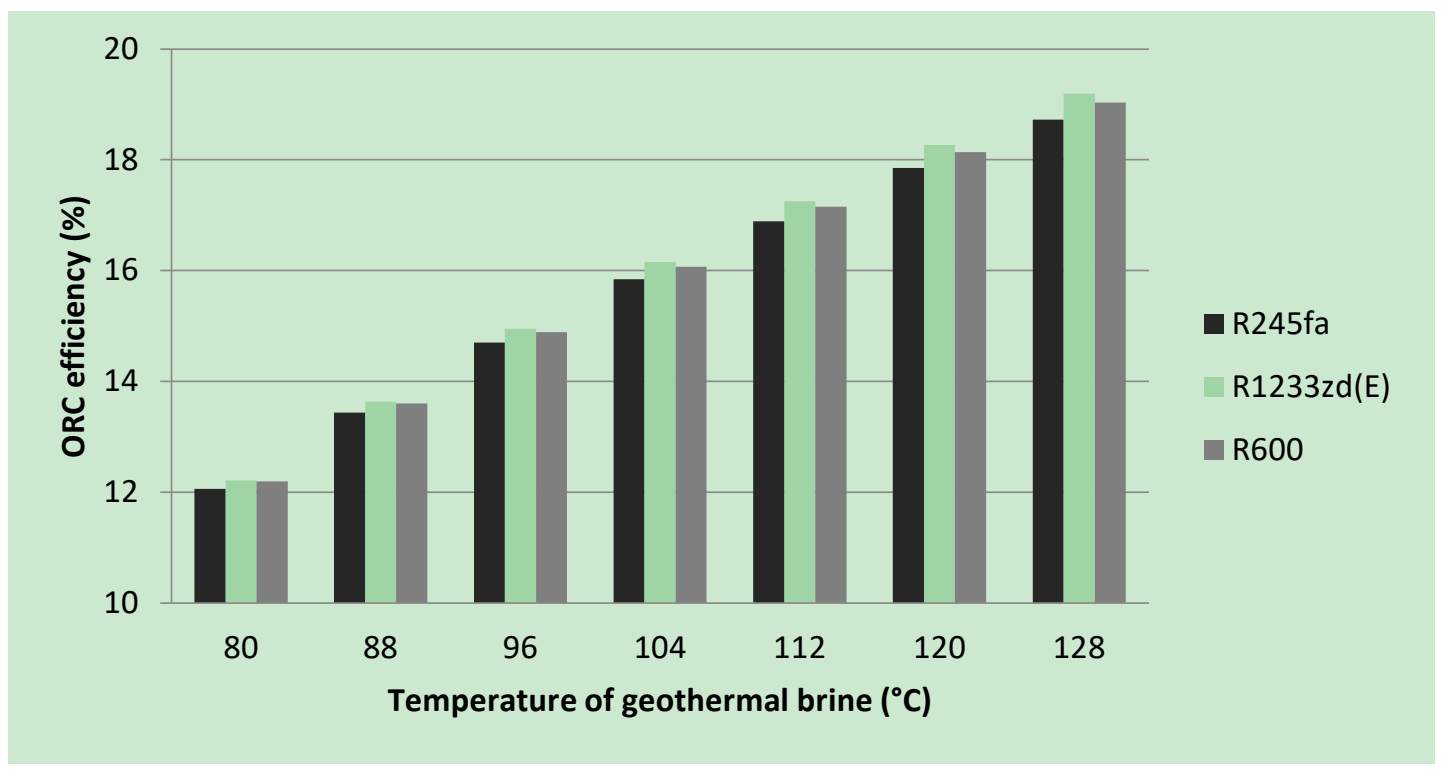

Figure 2. The efficiency of the ORC section in the modified system (assisted by gas turbine) as a function of the geothermal brine temperature. 
Figure 3 shows the electrical power only from ORC unit in the modified ORC cycle (with the geothermal brine heated by flue gases from gas turbine) for selected working fluids as a function of the geothermal brine temperature. Similarly, to the efficiency of the modified ORC system, the electric power increases with increasing temperature of the geothermal brine, reaching the highest values for R600 as the working medium (0.586-1.539 MW). However, the lowest power value is obtained for R1233zd (E) as a working fluid in the assumed conditions of the designed installation - this value increases from 0.569-1.363 MW with rising temperature of the geothermal brine. It is worth noting that the electric power of the modified ORC cycle mainly depends on the enthalpy difference during isentropic expansion of the ORC fluid's vapor in the turbine (pump operation is negligibly low in the ORC systems) and the mass flow of the ORC fluid's vapor in the turbine. For R600 the range of this difference is between 41.11 and $71.16 \mathrm{~kJ} / \mathrm{kg}$ with mass flow rates in the range of $14.25-21.62 \mathrm{~kg} / \mathrm{s}$. These differences take different values (from $21-37 \mathrm{~kJ} / \mathrm{kg}$ ) for R245fa and R1233zd (E) with slightly different mass flow rate values at the same brine temperatures-for R245fa it is $27.36-41.05 \mathrm{~kg} / \mathrm{s}$, while when for R1233zd (E)-26.46-36.37 kg/s. Differences in mass flow rates of ORC fluids (at the same geothermal brine temperatures) result from the adopted design assumptions and energy balances of individual parts of the installation.

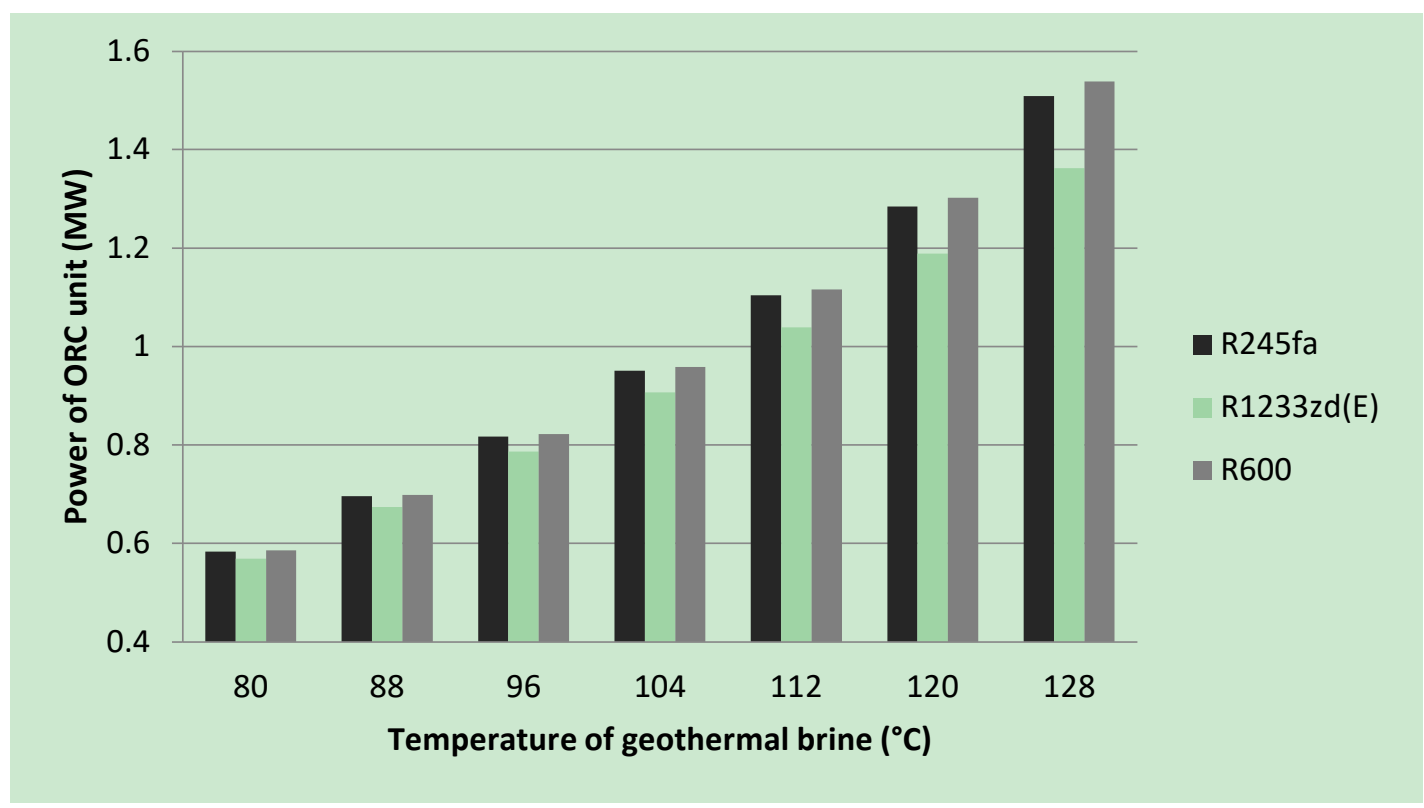

Figure 3. The power only from ORC unit in the modified ORC cycle (assisted by gas turbine) as a function of the geothermal brine temperature.

Figure 4 shows the total electrical power of the gas turbine and ORC power plant. Similarly, the increase in power of the overall system (geothermal ORC power plant with gas turbine) is the highest for R600 (5.683-6.609 MW), while the smallest for R1233zd (E) (5.670-6.463 MW). This is due to the assumption that the gas turbine generates a fixed amount of electricity of $5.1 \mathrm{MW}$. The electrical power of the designed installation increases with the increase in the temperature of the geothermal brine, with the rate of increase in power and temperature clearly higher for R600 and R245fa than R1233zd (E).

The change of the fossil fuel utilization factor (FFUF) for the designed installation as a function of the geothermal brine temperature is presented in Figure 5. As mentioned before, this ratio is defined as the ratio of combined system power to heat supplied from the combustion of fossil fuel in a gas turbine. The highest values are obtained for R600, and the lowest for R1233zd (E). It is worth noticing that for all considered working fluids, FFUF coefficient obtains higher values than for alone working 
gas turbine used in project, which proves that it is better to use these two technologies in a combined system than as individual systems for electricity production.

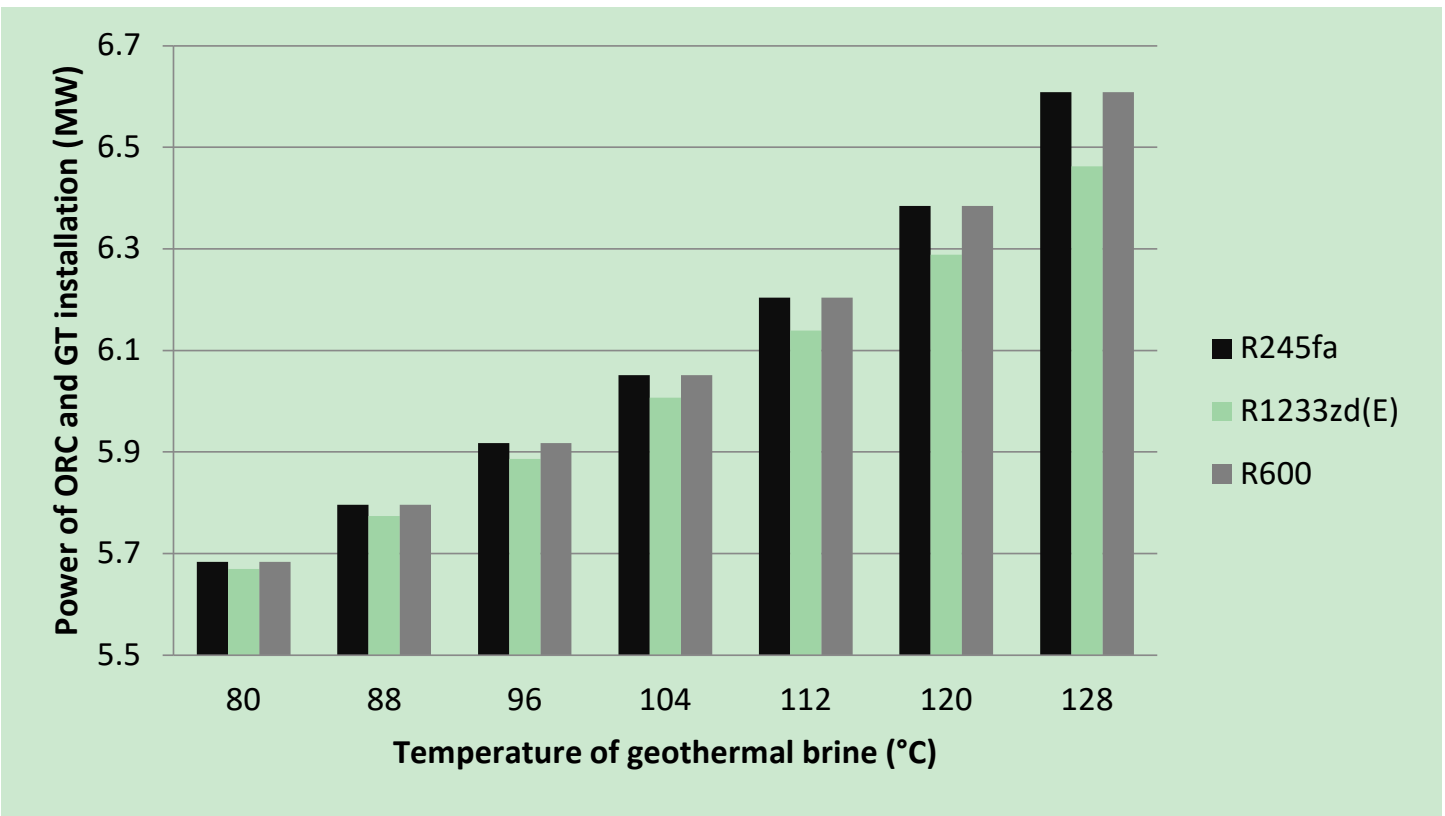

Figure 4. The power of the modified ORC system (assisted by gas turbine) as a function of the geothermal brine temperature.

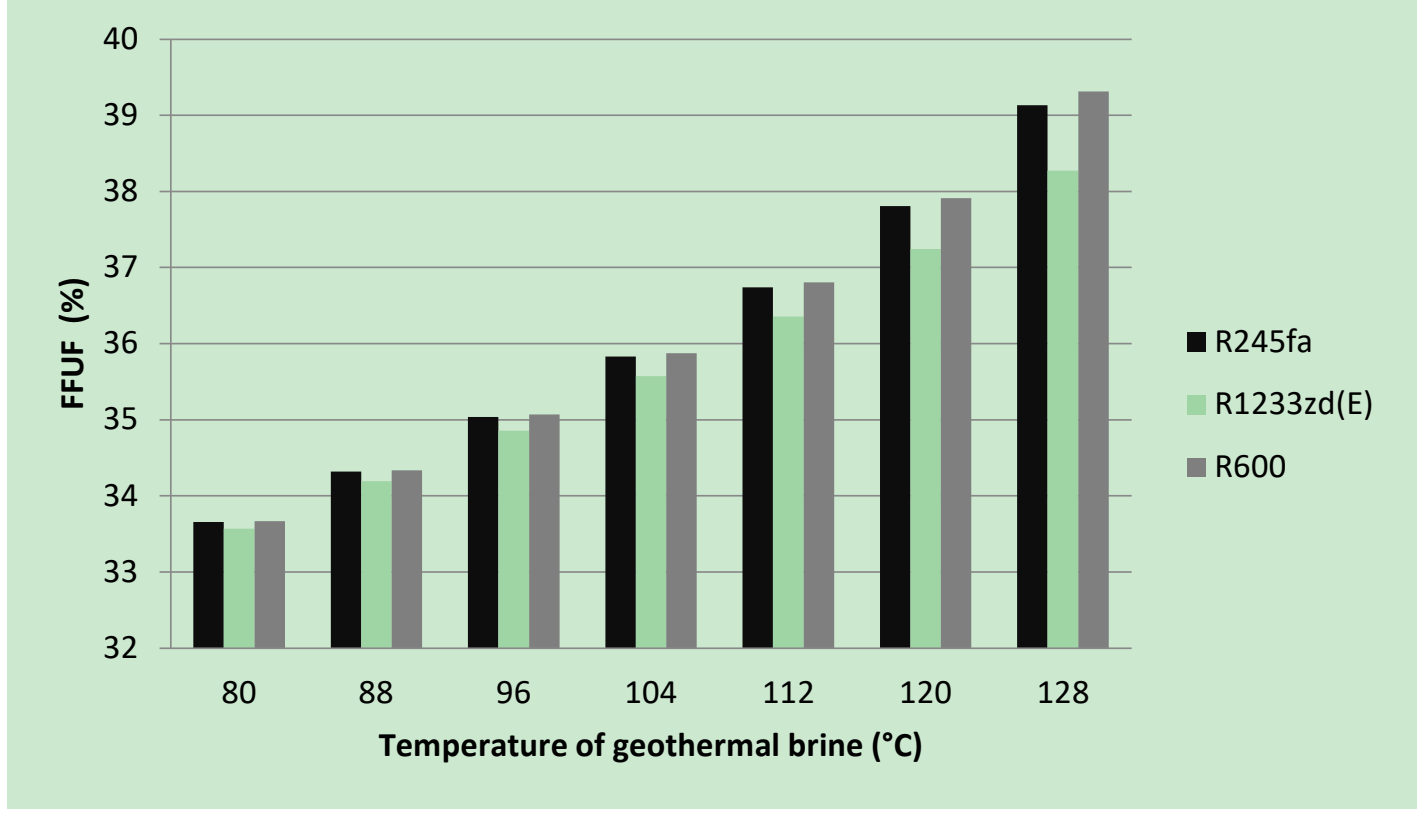

Figure 5. The fossil fuel utilization factor (FFUF) of the modified ORC system (assisted by gas turbine) as a function of the geothermal brine temperature.

The total efficiency of the designed system, i.e., the ORC geothermal power plant assisted by a gas turbine, is shown as a function of the geothermal brine temperature in Figure 6. Analyzing the results, as the temperature of the geothermal brine increases, the efficiency of the system decreases. This is related to the assumptions made in the project. The condensation temperature was rigidly set at $30{ }^{\circ} \mathrm{C}$, so in this case the pressure and evaporation temperature could be operated to increase the efficiency and power of the ORC circuit. However, this temperature is determined based on the evaporator's 
energy balance and depends on the temperature of the heated geothermal brine. This results in limited possibilities to increase the power of the ORC circuit and change certain operating parameters. It also affects the temperature of the geothermal brine after leaving the preheater-even with the least favorable parameters of the geothermal brine, the assumed amount of heat $(10 \mathrm{MW})$ for technological and/or heating purposes can be collected. The above-mentioned factors influence such that the overall efficiency of the designed installation decreases with increasing temperature. This efficiency is the lowest for R245fa (57.75-53.27\%), while the highest for R1233zd (E) (58.17-54.90\%).

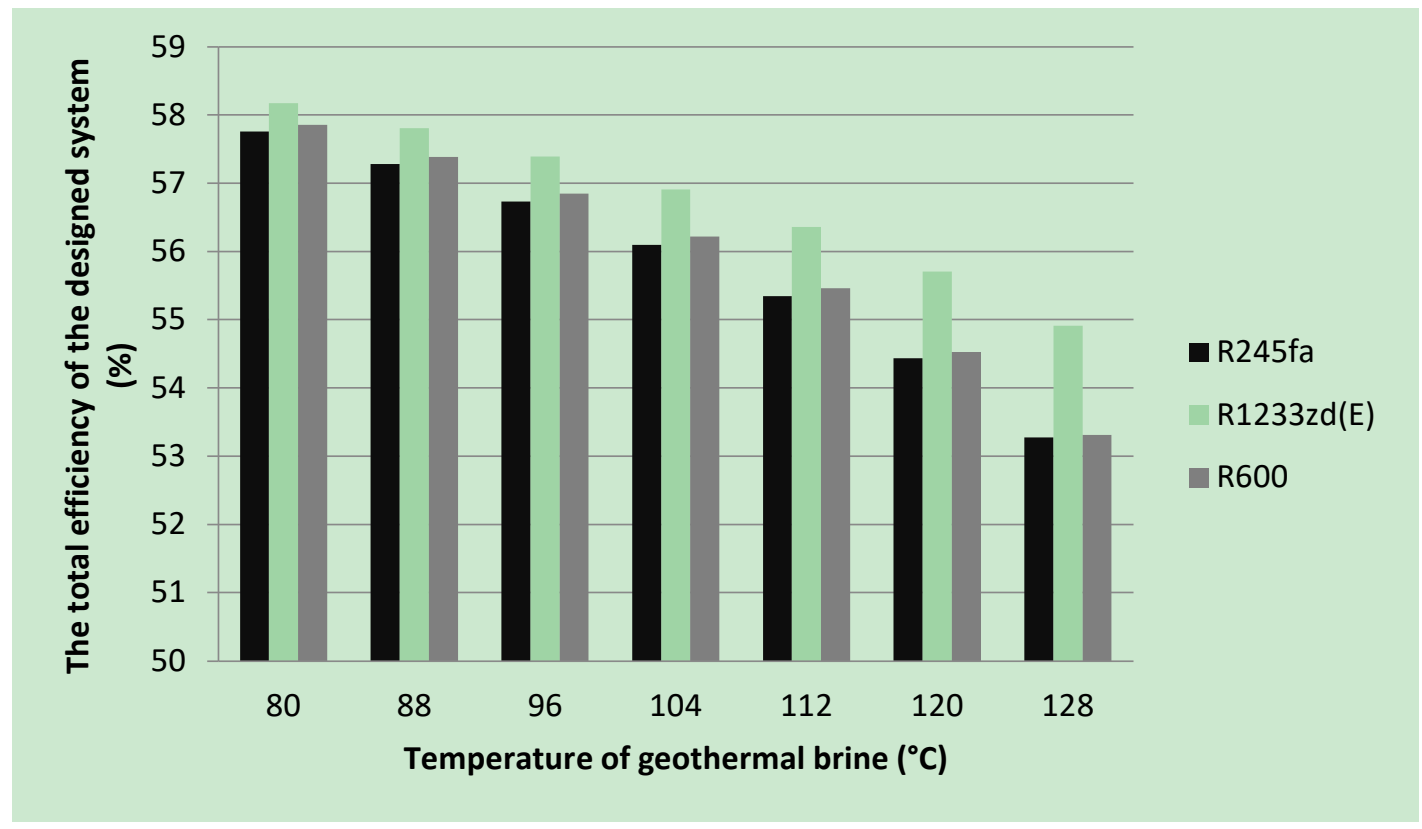

Figure 6. The total efficiency of the modified ORC system (assisted by gas turbine) as a function of the geothermal brine temperature.

Figure 7 presents the most important parameters for the designed installation on the example of the R600 as a working fluid-the summary of results is intended to illustrate the differences between certain indicators. The summary includes ORC efficiency, total efficiency of the modified system and the fossil fuel utilization factor (FFUF).

Considering that the gas turbine used to heat the geothermal brine had an electrical efficiency of $30.2 \%$, it can be observed what was mentioned earlier that the FFUF fuel use ratio is greater than both the efficiency of the ORC cycle in the modeled installation and the gas turbine efficiency. The overall efficiency of the system is relatively high and decreases as the temperature of the geothermal brine decreases-the reasons for this phenomenon have also been explained. 


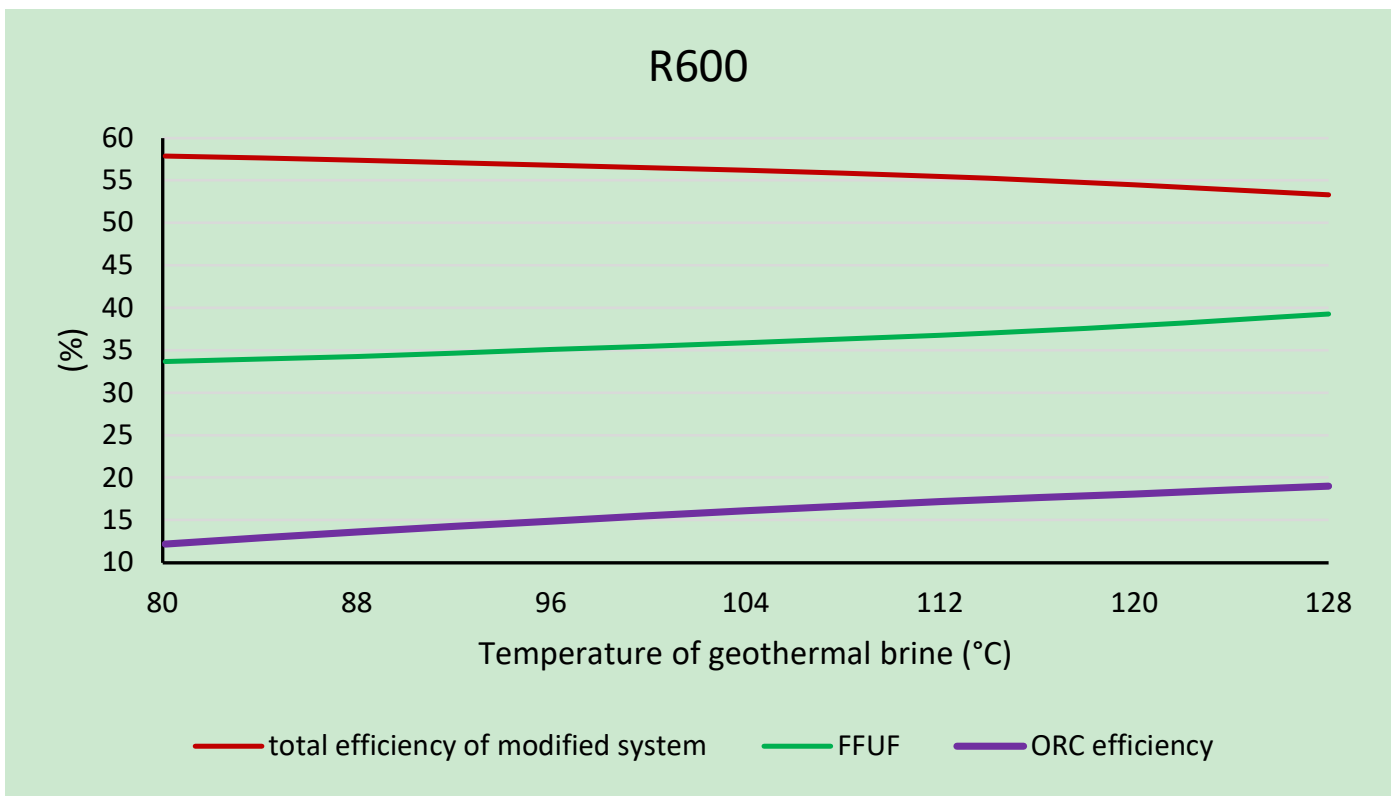

Figure 7. Summary of individual results for the designed modified ORC power plant supported by a gas turbine with R600 as a working fluid.

\subsection{Impact of Changing the Amount of Heat Produced on the System Parameters}

The design assumptions state that the system is to provide $10 \mathrm{MW}$ of heat for technological or heating purposes. As mentioned earlier, this assumption significantly affected the overall efficiency of the system-reducing the efficiency of the system with increasing temperature of the geothermal brine. Figure 8 presents the total efficiency of the designed system depending on the amount of heat supplied by this system (10 MW, $5 \mathrm{MW}$ and no heat receiver for technological and heating purposes).

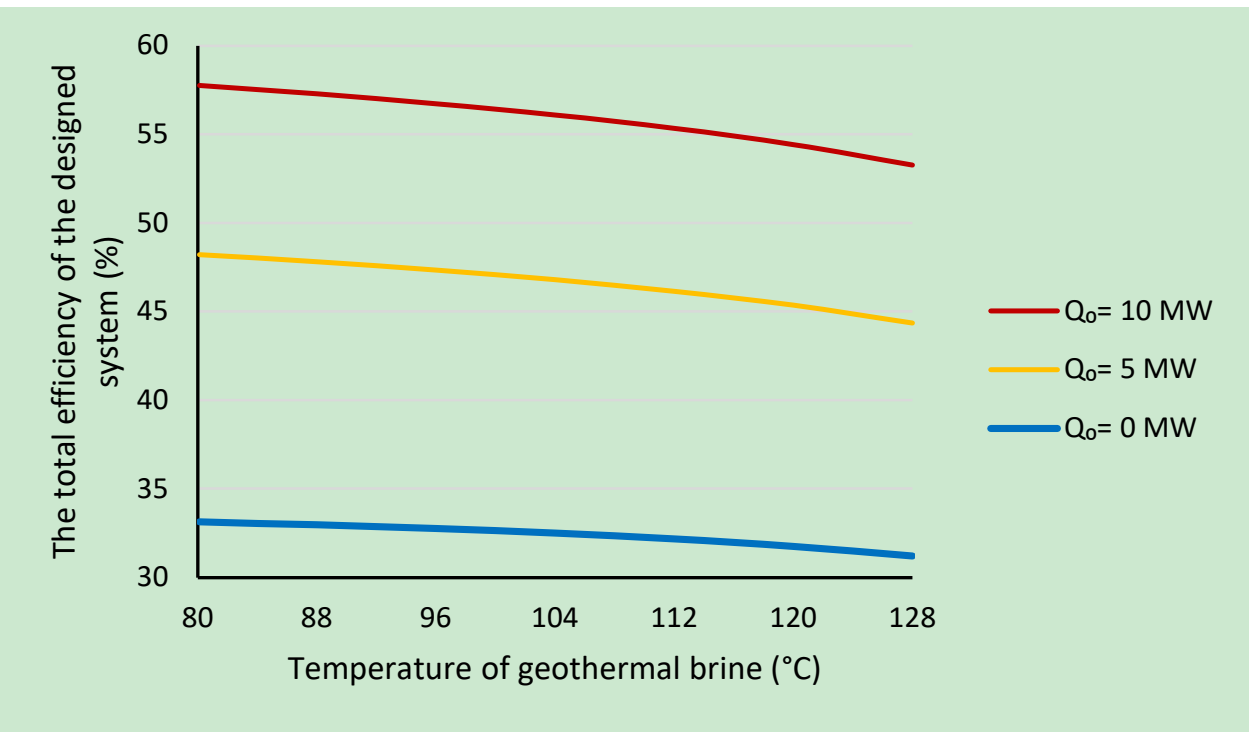

Figure 8. Impact of changing the amount of heat produced on the total efficiency of the proposed installation.

Increasing the amount of heat received from the system increases the efficiency of the entire system. As the temperature of the geothermal brine increases, we can see a decrease in the efficiency of the system - while the decrease is more rapid for systems producing heat. 


\subsection{Impact of the Gas Turbine Change on the System Parameters}

In this section, the impact of the turbine used to heat the geothermal brine on the parameters of the designed system was investigated. Two gas turbines of higher power GT-300 and GT-400 were used for this analysis, which were compared with the analyzed before GT-100 turbine and the ORC reference system (without gas turbine). The parameters of the turbines used in analysis are presented in Table 3. The analysis was carried out using R1233zd (E) as a working factor due to its negligible negative impact on the environment and modern design standards that strive for designing installations to be environmentally friendly.

Table 3. Comparison of the basic technical parameters of the GT-100, GT-300 and GT-400 gas turbines. Source: Own study based on [51].

\begin{tabular}{cccc}
\hline Type of the Gas Turbine & Gas Turbine GT-100 & Gas Turbine GT-300 & Gas Turbine GT-400 \\
\hline Fuel & & Natural gas, liquid fuel, dual fuel \\
Gross efficiency & $30.2 \%$ & $30.6 \%$ & $34.8 \%$ \\
Heat rate & $11,914 \mathrm{~kJ} / \mathrm{kWh}$ & $11,773 \mathrm{~kJ} / \mathrm{kWh}$ & $10,355 \mathrm{~kJ} / \mathrm{kWh}$ \\
Turbine speed & $17,384 \mathrm{rpm}$ & $14,010 \mathrm{rpm}$ & $9,500 \mathrm{rpm}$ \\
Pressure ration & $14.0: 1$ & $13.7: 1$ & $16.8: 1$ \\
Exhaust mass flow & $19.5 \mathrm{~kg} / \mathrm{s}$ & $30.2 \mathrm{~kg} / \mathrm{s}$ & $39.4 \mathrm{~kg} / \mathrm{s}$ \\
Exhaust temperature & $545^{\circ} \mathrm{C}$ & $542^{\circ} \mathrm{C}$ & $555^{\circ} \mathrm{C}$ \\
Power & $5.1 \mathrm{MW}_{\mathrm{e}}$ & $7.9 \mathrm{MW}$ & $12.9 \mathrm{MW}_{\mathrm{e}}$ \\
\hline
\end{tabular}

Figure 9 shows the impact of the gas turbine change on the efficiency of the ORC cycle in modified power plant assisted by this type of turbine. For comparative purposes, the efficiency of ORC power plant operating without gas turbine support has been added. Analyzing the results, the efficiency of the ORC cycle increases with increasing temperature of the geothermal brine. Also, the efficiency of ORC systems in a modified installation with used gas turbines is greater than the reference one. The efficiency of the reference ORC cycle (without gas turbine) reaches a range of $9.43-17.54 \%$ (depending on the temperature of the geothermal brine which vary in the range of $80-128^{\circ} \mathrm{C}$ ). When it comes to systems with gas turbines, the ORC cycle efficiency is obtained for a system with a GT-100 turbine-it ranges from $12.21 \%$ to $19.20 \%$ depending on the temperature of the geothermal brine. In turn, the system with the GT-400 turbine has the highest ORC cycle efficiency of the designed power plant-these values range from $14.78 \%$ to $20.71 \%$. The efficiency of the ORC cycle is influenced by the condensing temperature (which is assumed to be constant at $30{ }^{\circ} \mathrm{C}$ ) and the evaporation temperature, which indirectly depends on the mass flow and the temperature of the exhaust gases from the gas turbine system. The higher the mass flow and flue gases temperature are, the higher the evaporating temperature of the medium is, and thus the efficiency of the ORC cycle in the designed system. Looking at the parameters of the designed system, we can see that the exhaust mass flow increases from the turbine type GT-100, through GT-300, up to GT-400. When it comes to exhaust gases temperature, in the GT-300 turbine it is three degrees lower than in the GT-100; however, when comparing exhaust gas mass flows in these systems, this difference seems negligible. The GT-400 turbine is also characterized by the highest exhaust gases temperature, which affects its efficiency. 


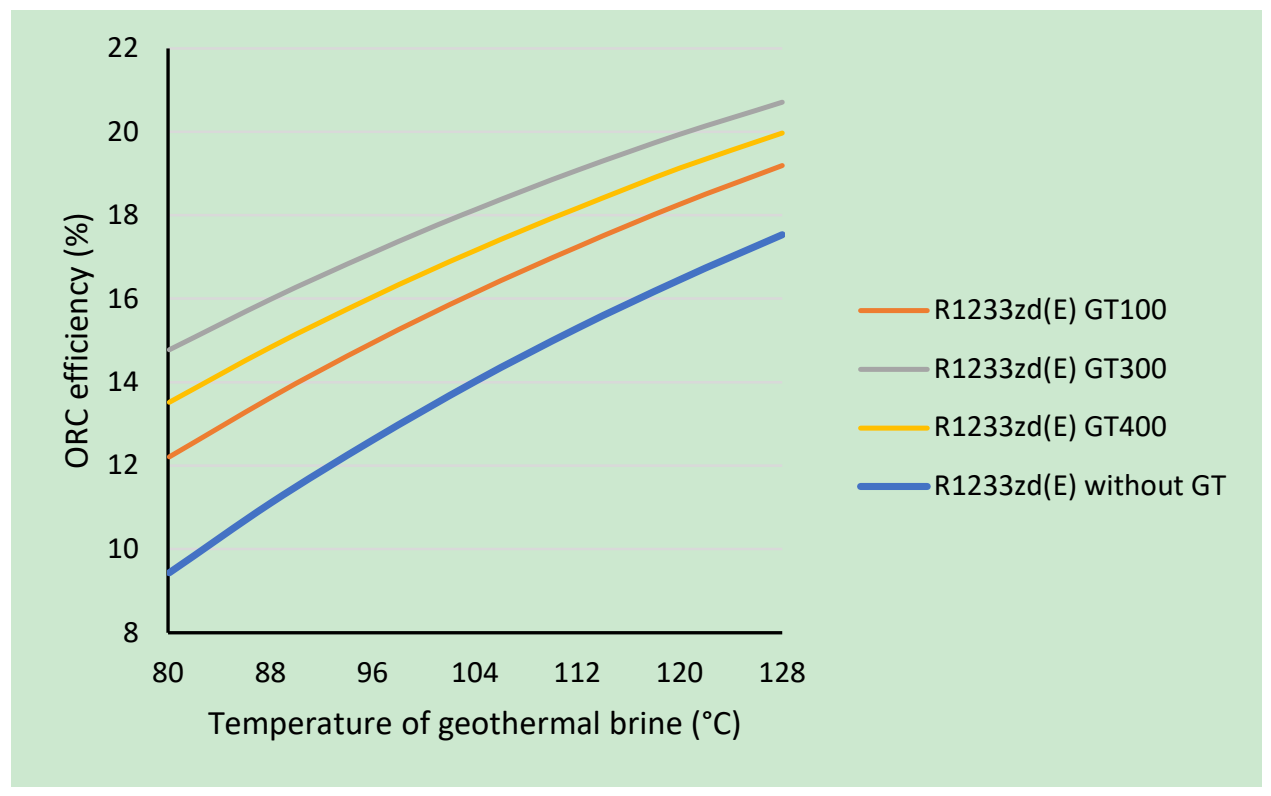

Figure 9. The efficiency of the ORC section in the modified system (assisted by gas turbine) as a function of the geothermal brine temperature with $\mathrm{R} 1233 \mathrm{zd}(\mathrm{E})$ as a working fluid for different gas turbine types.

The power of the ORC cycle in the designed installation depending on the type of turbine used is presented in Figure 10. The figure also includes a reference cycle that is not supported by a gas turbine system. The power of the ORC cycle increases as the temperature of the geothermal brine increases. The ORC cycle for the reference power plant (without gas turbine) has the lowest power (from 0.399 to $1.079 \mathrm{MW}$ depending on the geothermal brine temperature from $80-128^{\circ} \mathrm{C}$ ). Also, the system with the GT-100 turbine may show the lowest power from systems with gas turbines (0.569-1.363 MW), while the largest one is obtained for system with the GT-400 (0.771-1.812 MW). The power of the ORC cycle in proposed installation with GT-300 is between these two compartments and reaches values in the range of $0.665-1.555 \mathrm{MW}$ (depending on the temperature of the geothermal brine).

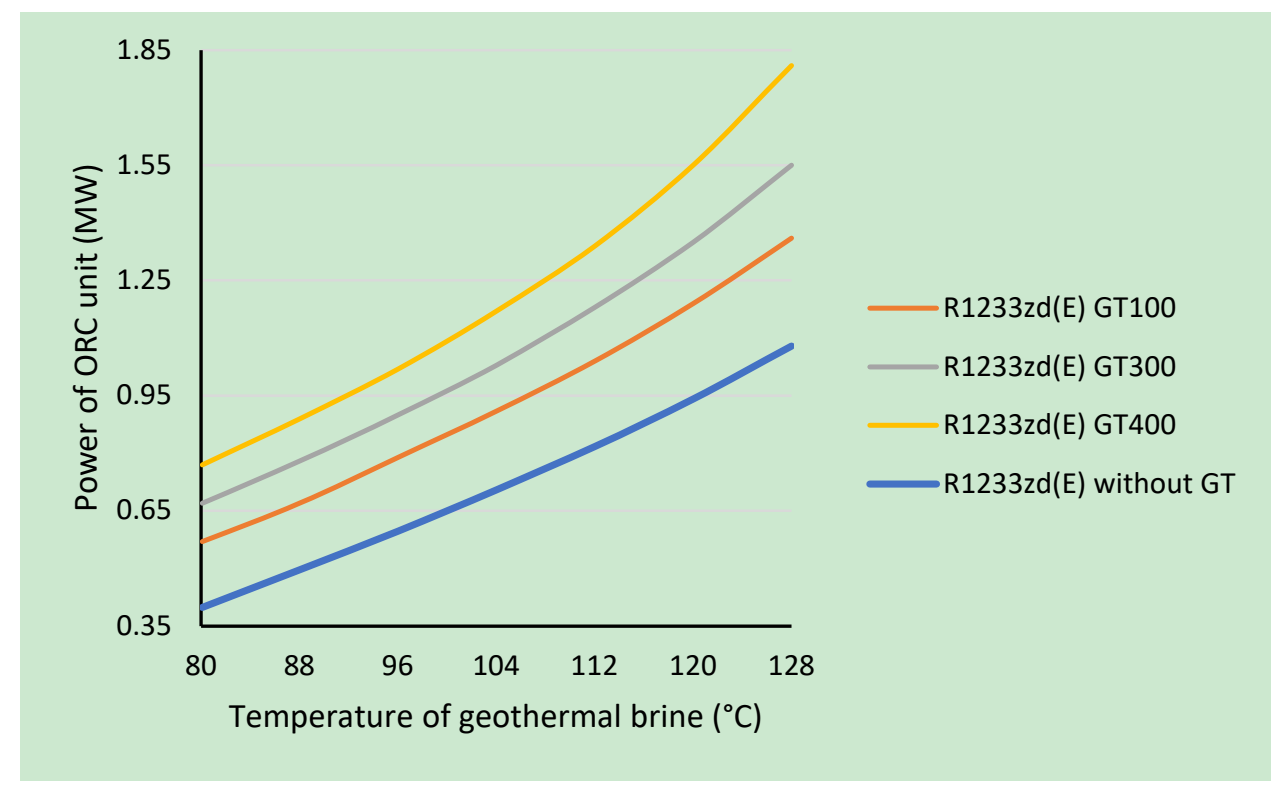

Figure 10. The power of ORC section in the modified system (assisted by gas turbine) as a function of the geothermal brine temperature with $\mathrm{R} 1233 \mathrm{zd}(\mathrm{E})$ as a working fluid for different gas turbine types. 
The total power of the modified ORC installation supported by gas turbine is significantly influenced by the electric power generated by a given gas turbine (Figure 11). The power generated by the gas turbine is significantly higher than that obtained from the ORC cycle. As shown in the figure-as the electric power of a gas turbine increases, the electric power of the entire system also increases. Similarly, to the ORC cycle power, the installation with GT-100 turbine has the lowest power reaching values from 5.670 to $6.463 \mathrm{MW}$ (depending on the temperature of the geothermal brine). The installation with the GT-400 turbine, on the other hand, has a total electrical power more than twice from that of the GT-100 turbine. The power of this system is in the range 13.671-14.712 MW changing with the change of the geothermal brine temperature, while the installation with the GT-300 turbine system reaches values between 8.565-9.455 MW.

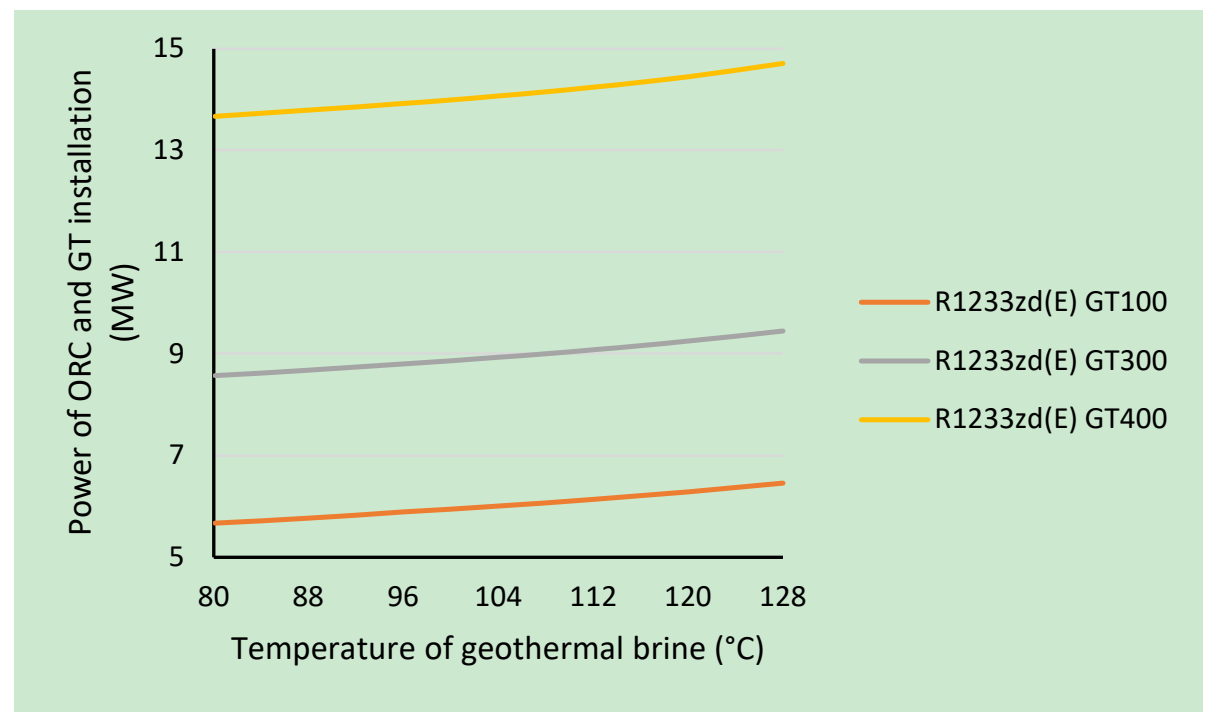

Figure 11. The power of modified ORC installation assisted by gas turbine as a function of the geothermal brine temperature with $\mathrm{R} 1233 \mathrm{zd}(\mathrm{E})$ as a working fluid for different gas turbine types.

The figure below (Figure 12) shows how the fossil fuel utilization factor (FFUF) changes for individual analyzed variants of designed installation depending on the geothermal brine temperature. For all the presented variants, these values increase with increasing the geothermal brine temperature and reach values higher than the efficiency of the ORC cycle-which only proves in favor of the designed installation. Interestingly, the smallest values in the range $33.17-36.69 \%$ are achieved for installations with the GT-300 turbine. The highest values are achieved for the variant with TG-400 turbine and they range from $36.88 \%$ to $39.69 \%$ depending on the geothermal brine temperatures. The highest growth rate of FFUF is observed for the GT-100 turbine variant and it ranges from $33.57 \%$ to $38.27 \%$.

The impact of the gas turbine used on the overall efficiency of the modified system is presented in Figure 13 below. Similarly, to the previously analyzed case (using various working fluids), the overall efficiency of the system decreases with increasing temperature of the geothermal brine. This is influenced by the assumed design conditions-a constant amount of heat produced-causing the worse use of geothermal heat along with the increase in the temperature of the geothermal brine. Interestingly, the overall efficiency of the design system is the highest for the variant with the GT-100 turbine (58.17-54.91\%), while the lowest for the variant with the GT-300 turbine (56.08-53.03\%). The GT-400 turbine variant adopts values from $57.02 \%$ to $53.80 \%$ depending on the temperature of the geothermal brine. It is worth noting that the values of the system overall efficiency do not change linearly with increasing gas turbine power. It is influenced by various factors associated with the analyzed types of turbines-in which there are no linear patterns related to the selected power, efficiency, temperature of 
the intake flue gases, as well as those associated with the selected ORC fluids (including the shape of the saturation curve).

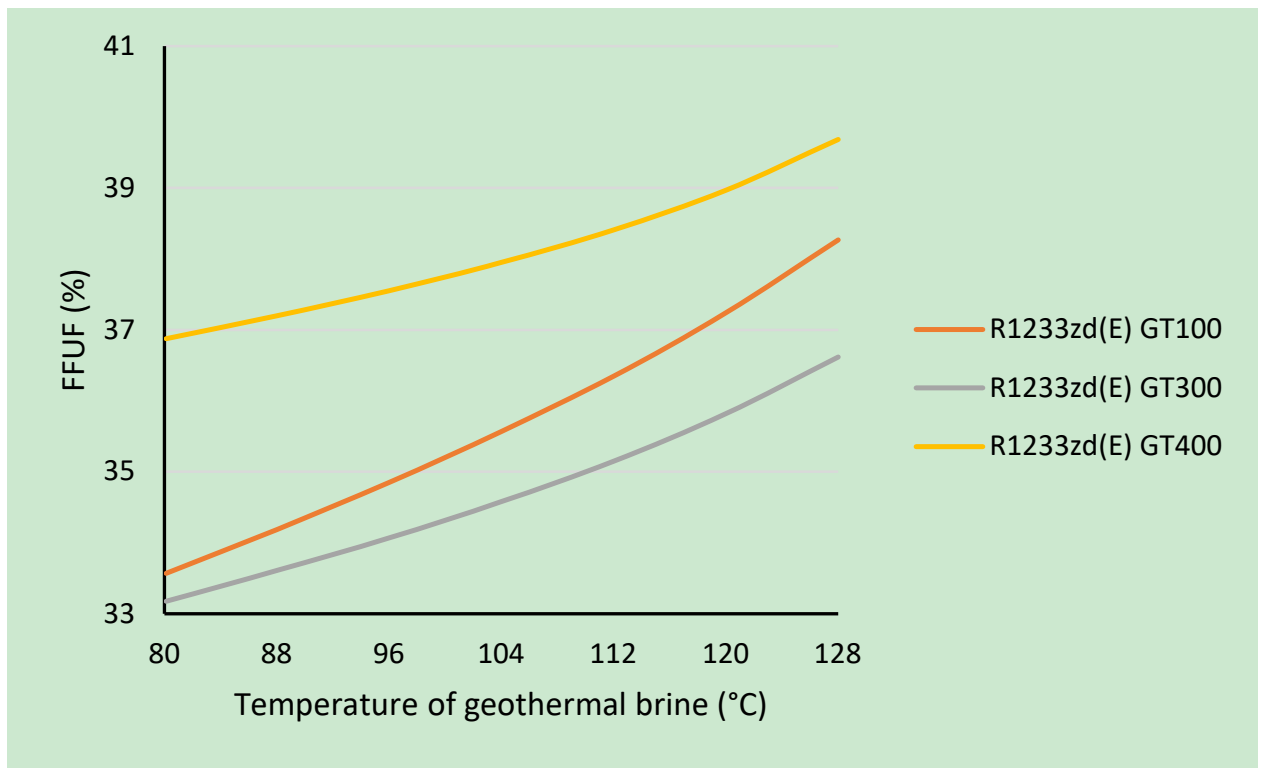

Figure 12. The fossil fuel utilization factor (FFUF) of modified ORC installation assisted by a gas turbine as a function of the geothermal brine temperature with R1233zd(E) as a working fluid for different gas turbine types.

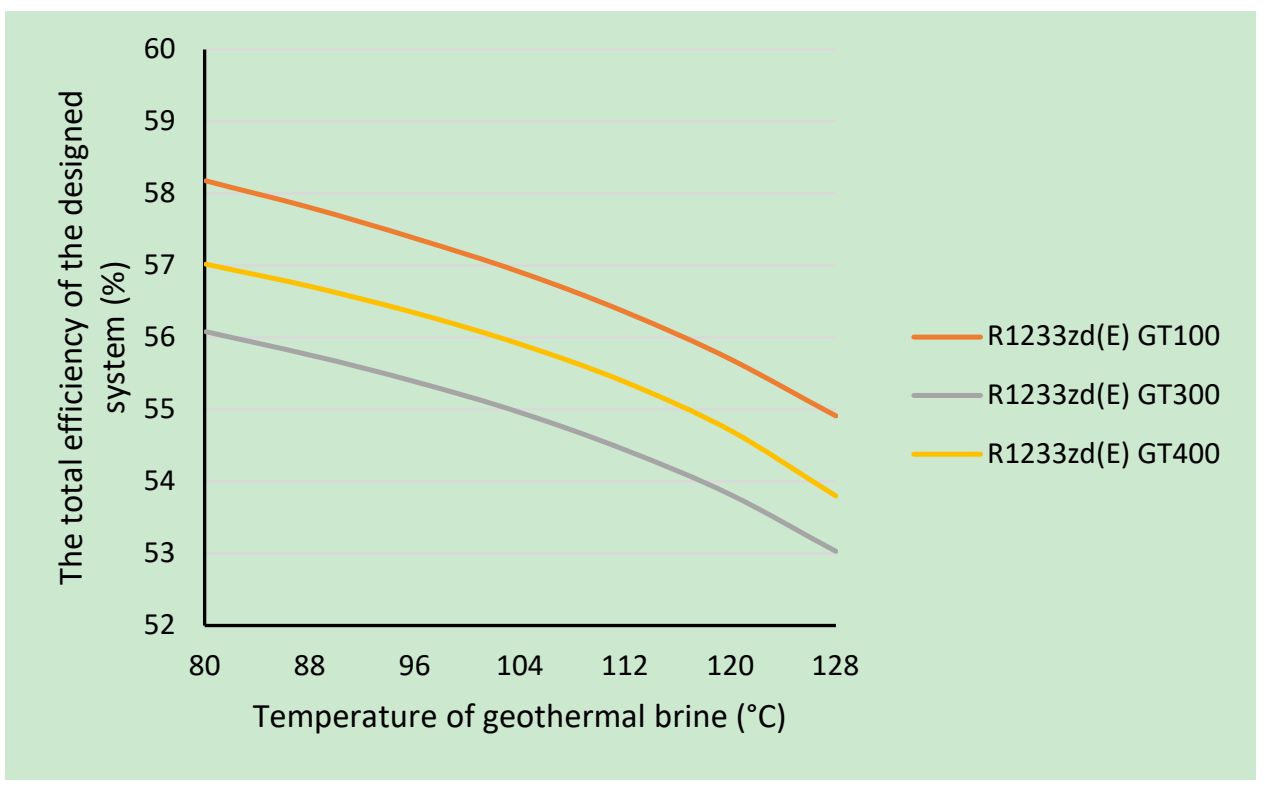

Figure 13. The total efficiency of modified ORC installation assisted by gas turbine as a function of the geothermal brine temperature with $\mathrm{R} 1233 \mathrm{zd}(\mathrm{E})$ as a working fluid for different gas turbine types.

This section analyzes the results obtained for various variants of the designed installation for the use of geothermal energy and natural gas. Significant parameters affecting the system efficiency, such as: ORC cycle efficiency, total system efficiency, ORC cycle power, electrical power of the modified installation, fossil fuel utilization factor (FFUF) depending on the geothermal brine temperature, used gas turbine, used ORC fluids are discussed in more detail 


\section{Conclusions}

The analyzes undertaken in this article are based on the energy policy of Poland and the EU and proposed development directions-among which are a reduction of the fossil fuel consumption, a decrease of harmful emissions and operating costs. These factors became the background and motivation of the undertaken work, which resulted in proposing a combined installation using a renewable energy source, in this case-geothermal energy. Considering the geothermal conditions in Poland (relatively low-temperature of the geothermal brine), a modified system with a gas turbine heating the geothermal brine using by the ORC unit was finally proposed. The analysis was carried out for a larger temperature range since it can be the starting point for other efficiency assessments for medium temperature geothermal energy.

The work presents the methodology for assessing the effectiveness of the designed installation - starting from the design assumptions for geothermal brine, through the gas turbine system, heat exchangers, to the ORC power plant and heat receiver for heating or technological purposes. The paper presents energy balance equations and detailed calculation methodology. Also, equations specifying individual parameters useful in assessing the energy efficiency of the proposed installation are given. The analysis was carried out for three working fluids for the ORC unit (R245fa, R600 and R1233zd (E)). Various variants of the designed installation were analyzed.

In the first variant, the influence of the working medium (R245fa, R600 and R1233zd (E)) on the individual parameters of the designed installation has been examined. The proposed installation consisted of the ORC power plant which used the geothermal heat from brine (with temperature of $80-128^{\circ} \mathrm{C}$ and mass stream of $100 \mathrm{~kg} / \mathrm{s}$ ) reheated by the flue gases from GT-100 gas turbine. Supplying exhaust gases from a gas turbine to the installation has a positive effect on the efficiency and power of the installation, which cause their increase. In the case of installations with R1233zd (E) as the working fluid, the ORC unit efficiency reaches values in the range of $12.21-19.20 \%$ depending on the temperature of the geothermal brine, which are higher than the values obtained for the installation not supported by the gas turbine system (efficiency from $9.43 \%$ to $17.54 \%$ ). In the proposed variant, an increase of the electric power of the ORC unit and the entire system is achieved (which is largely influenced by the power generated by the gas turbine system). In this case, the installation with the R600 as the working fluid achieves the highest values, and for ORC unit power this range is 0.586-1.539 MW, while for electric whole proposed installation 5.683-6.608 MW. The modified system reaches high efficiency for all analyzed working fluids, e.g., for R1233zd (E) ranges from $58.17 \%$ to $54.91 \%$ (depending on the geothermal brine temperature). This efficiency decreases with increasing temperature which is caused by design assumptions-a constant amount of heat received for heating and technological purposes.

Therefore, in the second variant, the effect of changing heat production on the overall efficiency of the system was examined, which increased with increasing demand.

In the third variant, the effect of changing the gas turbine type on individual system parameters has been analyzed. The gas turbine systems were selected from the same series-despite their selection from the series, no regularity could be found in changing their parameters (efficiency, power, temperature, and flue gas stream) - which reflect in the results. The ORC cycle power and the total electric power of modified installation have reached the highest value for the GT-400 turbine system and were respectively: $\mathrm{N}_{\mathrm{ORC}}=0.771-1.812 \mathrm{MW}$ and $\mathrm{N}_{\mathrm{ORC}}=13.671-14.712 \mathrm{MW}$.

Analyzing the obtained results, it can be concluded that both the efficiency and power of the cycle depend on the type of working fluid. However, in the case of organic working agents, it must be considered that they work efficiently in specific temperature and pressure ranges, which is why their proper selection is so important.

The combination of the gas turbine system with the ORC power plant gives positive effects in the form of increasing the parameters of the geothermal brine flowing into the superheater, and thus increasing the evaporation temperature of the ORC fluid (which affects the efficiency and power of the ORC cycle). 
Of course, the effects of power increase can be debatable- especially when we can more effectively use the energy of exhaust gases from a gas turbine system. This is due to the fact that the efficiency of the ORC cycle is relatively low, and all attempts to increase it usually take place at the expense of a significant amount of energy supplied to the system from the outside. This energy could be used for other purposes, e.g., heating or technological. Therefore, it is usually recommended to evaluate the effectiveness of this type of installation-usually the legitimacy of its use (with an additional source of heat) is when there is no practical application for heat, and there is a demand for electricity.

Author Contributions: All the authors have contributed toward developing and implementing the ideas and concepts presented in the paper. All the authors have collaborated to obtain the results and have been involved in preparing the manuscript. All authors have read and agreed to the published version of the manuscript.

Funding: This research received no external funding.

Conflicts of Interest: The authors declare no conflict of interest.

\section{Nomenclature}

\begin{tabular}{|c|c|}
\hline & \\
\hline $1,2,3,4,5, \mathrm{~A}, \mathrm{~B}, \mathrm{C}$ & thermodynamic state points \\
\hline h & specific enthalpy $(\mathrm{kJ} / \mathrm{kg})$ \\
\hline$\dot{m}_{G E O}$ & geothermal brine mass flow rate $(\mathrm{kg} / \mathrm{s})$ \\
\hline$\dot{m}_{O R C}$ & ORC fluid mass flow rate $(\mathrm{kg} / \mathrm{s})$ \\
\hline$\dot{m}_{S P}$ & exhaust gas mass flow rate $(\mathrm{kg} / \mathrm{s})$ \\
\hline $\mathrm{N}$ & electric power $(\mathrm{kW})$ \\
\hline Q & thermal power $(\mathrm{kW})$ \\
\hline $\mathrm{T}$ & Temperature (K) \\
\hline$\eta_{O R C}$ & ORC efficiency (\%) \\
\hline$\eta_{g}$ & generator efficiency $(\%)$ \\
\hline$\eta_{i P}$ & pump internal efficiency (\%) \\
\hline$\eta_{i P}$ & turbine internal efficiency $(\%)$ \\
\hline$\eta_{m}$ & turbine mechanical efficiency (\%) \\
\hline IN & at inlet \\
\hline OUT & at outlet \\
\hline Abbreviation & \\
\hline $\mathrm{DH}$ & District/ Process Heating \\
\hline FFUF & Fossil fuel utilization factor \\
\hline GEO & Geothermal \\
\hline GT & Gas Turbine \\
\hline GWP & Global Warming Potential \\
\hline $\mathrm{HC}$ & Hydrocarbon \\
\hline $\mathrm{HCF}$ & Hydrofluorocarbon \\
\hline $\mathrm{HCFO}$ & Hydrochlorofluoroolefin \\
\hline HFOs & Hydrofluoroolefins \\
\hline ODP & Ozone Depletion Potential \\
\hline ORC & Organic Rankine Cycle \\
\hline
\end{tabular}

\section{References}

1. Sadeghi, M.; Nemati, A.; Ghavimi, A.; Yari, M. Thermodynamic analysis and multi-objective optimization of various ORC (organic Rankine cycle) configurations using zeotropic mixtures. Energy 2016, 109, 791-802. [CrossRef]

2. Schuster, A.; Karellas, S.; Kakaras, E.; Spliethoff, H. Energetic and economic investigation of Organic Rankine Cycle applications. Appl. Therm. Eng. 2009, 29, 1809-1817. [CrossRef]

3. Zhai, H.; Dai, J.; Wu, J.Y.; Wang, R.Z. Energy and exergy analyses on a novel hybrid solar heating, cooling and power generation system for remote areas. Appl. Energy 2009, 86, 1395-1404. [CrossRef] 
4. Wang, R.; Jiang, L.; Ma, Z.; Gonzalez-Diaz, A.; Wang, Y.; Roskilly, A.P. Comparative analysis of small-scale organic Rankine cycle systems for solar energy utilisation. Energies 2019, 12, 829. [CrossRef]

5. Mahlia, T.M.I.; Syaheed, H.; Abas, A.E.P.; Kusumo, F.; Shamsuddin, A.H.; Ong, H.C.; Bilad, M.R. Organic Rankine Cycle (ORC) system applications for solar energy: Recent technological advances. Energies 2019, 12, 829. [CrossRef]

6. Heberle, F.; Brüggemann, D. Thermo-economic evaluation of organic rankine cycles for geothermal power generation using zeotropic mixtures. Energies 2015, 8, 2097-2124. [CrossRef]

7. DiPippo, R. Geothermal Power Plants, 3rd ed.; Butterworth-Heinemann: Oxford, UK, 2013.

8. Heberle, F.; Brüggemann, D. Exergy based fluid selection for a geothermal Organic Rankine Cycle for combined heat and power generation. Appl. Therm. Eng. 2010, 30, 1326-1332. [CrossRef]

9. Lentz, Á.; Almanza, R. Solar-geothermal hybrid system. Appl. Therm. Eng. 2006, 26, 1537-1544. [CrossRef]

10. Borsukiewicz-Gozdur, A.; Nowak, W. Comparative analysis of natural and synthetic refrigerants in application to low temperature Clausius-Rankine cycle. Energy 2007, 32, 344-352. [CrossRef]

11. Hettiarachchi, H.M.; Golubovic, M.; Worek, W.; Ikegami, Y. Optimum design criteria for an Organic Rankine cycle using low-temperature geothermal heat sources. Energy 2007, 32, 1697-1706. [CrossRef]

12. Guo, T.; Wang, H.X.; Zhang, S.J. Selection of working fluids for a novel low-temperature geothermally-powered ORC based cogeneration system. Energy Convers. Manag. 2011, 52, 2384-2391. [CrossRef]

13. Shengjun, Z.; Huaixin, W.; Tao, G. Performance comparison and parametric optimization of subcritical Organic Rankine Cycle (ORC) and transcritical power cycle system for low-temperature geothermal power generation. Appl. Energy 2011, 88, 2740-2754. [CrossRef]

14. Saleh, B.; Koglbauer, G.; Wendland, M.; Fischer, J. Working fluids for low-temperature organic Rankine cycles. Energy 2007, 32, 1210-1221. [CrossRef]

15. Desideri, U.; Bidini, G. Study of possible optimisation criteria for geothermal power plants. Energy Convers. Manag. 1997, 38, 1681-1691. [CrossRef]

16. Bruhn, M. Hybrid-geothermal-fossil electricity generation from low enthalpy geothermal resources: Geothermal feedwater preheating in conventional power plants. Energy 2002, 27, 329-346. [CrossRef]

17. Borsukiewicz-Gozdur, A. Dual-fluid-hybrid power plant co-powered by low-temperature geothermal water. Geothermics 2010, 39, 170-176. [CrossRef]

18. Invernizzi, C.M.; Ayub, A.; Di Marcoberardino, G.; Iora, P. Pure and hydrocarbon binary mixtures as possible alternatives working fluids to the usual organic rankine cycles biomass conversion systems. Energies 2019, 12, 829. [CrossRef]

19. Algieri, A.; Morrone, P. Techno-economic analysis of biomass-fired ORC systems for single-family combined heat and power (CHP) applications. Energy Procedia 2014, 45, 1285-1294. [CrossRef]

20. Pezzuolo, A.; Benato, A.; Stoppato, A.; Mirandola, A. Fluid selection and plant configuration of an ORC-biomass fed system generating heat and/or power. Energy Procedia 2016, 101, 822-829. [CrossRef]

21. Dong, L.; Liu, H.; Riffat, S. Development of small-scale and micro-scale biomass-fuelled CHP systems-A literature review. Appl. Therm. Eng. 2009, 29, 2119-2126. [CrossRef]

22. Drescher, U.; Brüggemann, D. Fluid selection for the Organic Rankine Cycle (ORC) in biomass power and heat plants. Appl. Therm. Eng. 2007, 27, 223-228. [CrossRef]

23. Bălănescu, D.T.; Homutescu, V.M. Performance analysis of a gas turbine combined cycle power plant with waste heat recovery in Organic Rankine Cycle. Procedia Manuf. 2019, 32, 520-528. [CrossRef]

24. Bianchi, M.; Branchini, L.; Pascale, A.D.; Melino, F.; Ottaviano, S.; Peretto, A.; Torricelli, N.; Zampieri, G. Performance and operation of micro-ORC energy system using geothermal heat source. Energy Procedia 2018, 148, 384-391. [CrossRef]

25. Galanis, N.; Cayer, E.; Roy, P.; Denis, E.S.; Désilets, M. Electricity generation from low temperature sources. J. Appl. Fluid Mech. 2009, 2, 66-67.

26. Tempesti, D.; Manfrida, G.; Fiaschi, D. Thermodynamic analysis of two micro CHP systems operating with geothermal and solar energy. Appl. Energy 2012, 97, 609-617. [CrossRef]

27. Hung, T.C.; Shai, T.Y.; Wang, S.K. A review of organic rankine cycles (ORCs) for the recovery of low-grade waste heat. Energy 1997, 22, 661-667. [CrossRef]

28. Chen, H.; Goswami, D.Y.; Stefanakos, E.K. A review of thermodynamic cycles and working fluids for the conversion of low-grade heat. Renew. Sustain. Energy Rev. 2010, 14, 3059-3067. [CrossRef] 
29. Quoilin, S.; Declaye, S.; Tchanche, B.F.; Lemort, V. Thermo-economic optimization of waste heat recovery Organic Rankine Cycles. Appl. Therm. Eng. 2011, 31, 2885-2893. [CrossRef]

30. Fernández, F.J.; Prieto, M.M.; Suárez, I. Thermodynamic analysis of high-temperature regenerative organic Rankine cycles using siloxanes as working fluids. Energy 2011, 36, 5239-5249. [CrossRef]

31. Liu, W.; Meinel, D.; Wieland, C.; Spliethoff, H. Investigation of hydrofluoroolefins as potential working fluids in organic Rankine cycle for geothermal power generation. Energy 2014, 67, 106-116. [CrossRef]

32. Matuszewska, D.; Sztekler, K.; Gorski, J. An influence of low-stability region on dense gas phenomena and their peculiarities in the ORC fluids. MATEC Web Conf. 2014, 18, 3005. [CrossRef]

33. Dai, Y.; Wang, J.; Gao, L. Parametric optimization and comparative study of organic Rankine cycle (ORC) for low grade waste heat recovery. Energy Convers. Manag. 2009, 50, 576-582. [CrossRef]

34. Nami, H.; Ertesvåg, S.; Agromayor, R.; Riboldi, L.; Nord, L.O. Gas turbine exhaust gas heat recovery by organic Rankine cycles (ORC) for offshore combined heat and power applications-Energy and exergy analysis. Energy 2018, 165, 1060-1071. [CrossRef]

35. Peris, B.; Navarro-Esbrí, J.; Molés, F. Bottoming organic Rankine cycle configurations to increase Internal Combustion Engines power output from cooling water waste heat recovery. Appl. Therm. Eng. 2013, 61, 364-371. [CrossRef]

36. Di Battista, D.; Mauriello, M.; Cipollone, R. Waste heat recovery of an ORC-based power unit in a turbocharged diesel engine propelling a light duty vehicle. Appl. Energy 2015, 152, 109-120. [CrossRef]

37. Douvartzides, S.; Karmalis, I. Working fluid selection for the Organic Rankine Cycle (ORC) exhaust heat recovery of an internal combustion engine power plant. IOP Conf. Ser. Mater. Sci. Eng. 2013, 161, 012087.

38. Carcasci, C.; Ferraro, R.; Miliotti, E. Thermodynamic analysis of an organic Rankine cycle for waste heat recovery from gas turbines. Energy 2014, 65, 91-100. [CrossRef]

39. Clemente, S.; Micheli, D.; Reini, M.; Taccani, R. Bottoming organic Rankine cycle for a small scale gas turbine: A comparison of different solutions. Appl. Energy 2013, 106, 355-364. [CrossRef]

40. Khaljani, M.; Khoshbakhti Saray, R.; Bahlouli, K. Thermodynamic and thermoeconomic optimization of an integrated gas turbine and organic Rankine cycle. Energy 2015, 93, 2136-2145. [CrossRef]

41. Lecompte, S.; Huisseune, H.; Van Den Broek, M.; Vanslambrouck, B.; De Paepe, M. Review of organic Rankine cycle (ORC) architectures for waste heat recovery. Renew. Sustain. Energy Rev. 2015, 47, 448-461. [CrossRef]

42. Shokati, N.; Mohammadkhani, F.; Yari, M.; Mahmoudi, S.M.; Rosen, M.A. A comparative exergoeconomic analysis of waste heat recovery from a gas turbine-modular helium reactor via organic rankine cycles. Sustainability 2014, 6, 2474-2489. [CrossRef]

43. Zare, V.; Mahmoudi, S.M. A thermodynamic comparison between organic rankine and kalina cycles for waste heat recovery from the gas turbine-modular helium reactor. Energy 2014, 79, 398-406. [CrossRef]

44. Bidini, G.; Desideri, U.; Di Maria, F.; Baldacci, A.; Papale, R.; Sabatelli, F. Optimazation of an integrated gas turbine-geothermal power plant. Energy Convers. Manag. 1998, 39, 1945-1956. [CrossRef]

45. Astina, I.M.; Pastalozi, M.; Sato, H. An Improved hybrid and cogeneration cycle for enhanced. In Proceedings of the World Geothermal Congress 2010, Bali, Indonesia, 25-29 April 2010.

46. Nowak, W.; Stachel, A.A. Assessment of effectiveness of operation of geothermal ORC power plant, co-supplied exhaust Energy from gas turbine. Geol. Explor. Technol. 2011, 50, 145-156.

47. Chacartegui, R.; Sánchez, D.; Muñoz, J.M.; Sánchez, T. Alternative ORC bottoming cycles FOR combined cycle power plants. Appl. Energy 2015, 86, 2162-2170. [CrossRef]

48. Kanoglu, M.; Dincer, I. Performance assessment of cogeneration plants. Energy Convers. Manag. 2009, 50, 76-81. [CrossRef]

49. NIST. NIST Reference Fluid Thermodynamic and Transport Properties Database (REFPROP): Version 10; NIST: Gaithersburg, MD, USA, 2019.

50. Górecki, W. Atlas of Geothermal Resources of Mesozoic Formations in the Polish Lowlands; SE AGH; Warszawa, Poland, 2006.

51. Siemens/Reliable Gas Turbines 2019. Available online: https://new.siemens.com/global/en/products/energy/ power-generation/gas-turbines.html (accessed on 30 September 2019). 
52. Honeywell. Honeywell Solstice ${ }^{\circledR} 1233 z d($ E) Technical Information; Honeywell: Charlotte, NC, USA, 2013.

53. Al-Weshahi, M.A. Working fluid selection of low grade heat geothermal Organic Rankine Cycle (ORC). Int. J. Therm. Technol. 2014, 4, 6-12. [CrossRef]

54. Eyerer, S.; Dawo, F.; Kaindl, J.; Wieland, C.; Spliethoff, H. Experimental investigation of modern ORC working fluids R1224yd(Z) and R1233zd(E) as replacements for R245fa. Appl. Energy 2019, 240, 946-963. [CrossRef]

55. Bao, J.; Zhao, L. A review of working fluid and expander selections for organic Rankine cycle. Renew. Sustain. Energy Rev. 2013, 24, 325-342. [CrossRef]

(C) 2020 by the authors. Licensee MDPI, Basel, Switzerland. This article is an open access article distributed under the terms and conditions of the Creative Commons Attribution (CC BY) license (http://creativecommons.org/licenses/by/4.0/). 